\title{
Design and Build of a Solar Panel Integration Dryer and Temperature Controller with Autocad Inventor
}

\section{Rancang Bangun Alat Pengering Integrasi Panel Surya dan Pengontrol Suhu Dengan Autocad Inventor}

\author{
Nalendro Mataram ${ }^{1}$, Muhammad Dimas Adjie ${ }^{2}$, Anis Siti Nurrohkayati ${ }^{3}$ \\ \{nmataram12@gmail.com¹, dimasadjie83@gmail.com ${ }^{2}$, asn826@gmail.com ${ }^{3}$ \} \\ Jl. Ir. H. Juanda No.15, Sidodadi, Kec. Samarinda Ulu, Kota Samarinda, Kalimantan Timur ${ }^{123}$
}

\begin{abstract}
Drying is a mandatory process carried out after harvest or production. Direct drying is a traditional method that is still used today, but this method has drawbacks because it depends on the weather. Pests, the rainy season, and at night are obstacles experienced in this process. This dryer can help solve common solutions for manufacturers. A dryer coated with clear acrylic it can protect the produce from rain, dust, and pests. The solar panel functions as a power source for the temperature controller in the dryer. 40-50 C is the right temperature when drying, it is not recommended that temperatures exceed 50 because it can cause dry food ingredients outside. Incandescent lamps and mini fans are temperature control devices to stabilize the temperature inside with temperatures of $40^{\circ}$ to $50 \mathrm{C}$. Incandescent lamps also allow manufacturers to dry at night so that the drying process can be shorter than usual. The result found by the dryer is that it has a cross-sectional area of $2100 \mathrm{~cm}^{2}$ with a maximum capacity of 13 pieces with a diameter of $7 \mathrm{~cm}$. The drying rate with the sun reaches $0.6 \%$ per hour, and the energy needed by the sun for 10 hours of drying is $36288 \mathrm{~kJ}$. The power that can be produced by solar panels is 100 watts with the electrical energy needed for 10 hours of drying with a controller of $3600 \mathrm{~J}$.
\end{abstract}

Keywords - Dryer; Solar panels; temperature control

Abstrak. Pengeringan adalah proses wajib yang dilakukan pasca panen atau produksi. Menjemur langsung adalah cara tradisional yang masih dipakai hingga sekarang, tetapi cara ini memiliki kelemahan karena bergantung dengan cuaca. Gangguan hama, musim hujan, serta malam hari adalah hambatan yang dialami pada proses ini. Alat pengering ini dapat membantu memecahkan solusi yang biasa dialami oleh produsen. Dengan alat pengering yang dilapisi oleh akrilik bening dapat melindungi hasil produksi dari hujan, debu, dan hama. Solar panel berfungsi sebagai sumber daya dari pengontrol suhu yang terdapat di alat pengering. 40-50 C menjadi suhu yang pas saat pengeringan, tidak disarankan suhu melampaui $50^{\circ}$ dikarenakan dapat mengakibatkan bahan pangan kering diluar. Lampu pijar dan kipas mini fan menjadi alat pengatur kontrol suhu untuk menstabilkan suhu didalam dengan temperature $40^{\circ}$ hingga $50^{\circ} \mathrm{C}$. Lampu pijar juga memungkinkan produsen melakukan pengeringan di malam hari sehingga proses pengeringan bisa lebih singkat dari biasanya. Hasil yang didapati oleh alat pengering tersebut adalah, memiliki luas penampang sebesar $2100 \mathrm{~cm}^{2}$ dengan kapasitas maksimum yaitu 13 pcs rengginang dengan diameter $7 \mathrm{~cm}$. Laju pengeringan dengan matahari mencapai $0.6 \%$ per jam, dan energy yang dibutuhkan matahari selama 10 jam pengeringan adalah $36288 \mathrm{~kJ}$. Daya yang dapat dihasilkan oleh panel surya sebesar 100 watt dengan energi listrik yang dibutuhkan untuk 10 jam pengeringan dengan kontroler sebesar 3600J.

Kata Kunci - Alat Pengering; Panel surya; pengatur suhu

\section{Pendahuluan}

Pengeringan adalah suatu proses dimana produk akan menjadi awet dengan cara menghilangkan kadar air yang berada di dalam produk tersebut dengan menggunakan panas. Produk olahan yang cocok untuk dilakukan pengeringan adalah kerupuk, rengginan, biji-bijian, hingga ikan asin. Selain untuk mengurangi kadar air, tujuan pengeringan adalah untuk memperpanjang waktu kadaluarsa dari sebuah produk. Hal tersebut terjadi karena mikroorganisme dalam air dari produk akan mati karena panas. Hal tersebut mengakibatkan produk memiliki volume yang lebih kecil sehingga dapat menghemat ruang simpan dari produk [1].

Metode untuk pengeringan beranekaagam ada yang dilakukan secara alami dengan matahari dan menggunakan oven sebagai sumber panas. Produsen UMKM biasa menggunakan metode alami karena dinilai lebih sederhana dan murah. Metode alami biasanya menggunakan tikar, terpal hingga aspal sebagai alat dari menjemur, namun produsen lebih memilih tikar atau terpal. Tetapi metode ini memiliki kekurangan yaitu membutuhkan ruang yang luas, sehingga luasnya ruang jemur berbanding lurus dengan banyaknya produk yang dapat dikeringkan [2].

Terdapat metode lain yaitu pengeringan secara mekanis atau pengering buatan. Metode ini bekerja dengan menambahkan sumber panas lain daripada bergantung hanya dengan panas radiasi matahari. Metode ini memiliki 
keuntungan yaitu produsen dapat menentukan kapasitas sendiri, mengatur panas dalam ruang jemur, dan tidak memerlukan ruang yang luas karena metode ini memungkinkan produsen untuk menjemur secara bertingkat.

Tujuan dari penelitian ini adalah memberikan system pengontrol suhu berbasis arduino dengan lampu pijar sebagai alat bantu panas dan kipas computer sebagai alat bantu pendingin atau keluarnya udara panas. Jenis arduino yang digunakan adalah arduino mega 2560 Rev3 lalu dihubungkan ke relay yang nantinya akan dicabangkan ke lampu pijar dan kipas mini komputer dengan dimensi 4x4 cm. produsen akan memantau dan mengatur suhu lampu pijar san kipas melalui LCD 1602 16x2 dengan controlernya. Sedangkan untuk mengetahui suhu di dalam ruang terdapat komponen dht 11 .

\section{METODE}

Metodologi penelitian perancangan alat penjemur diberikan dengan gambar berikut :

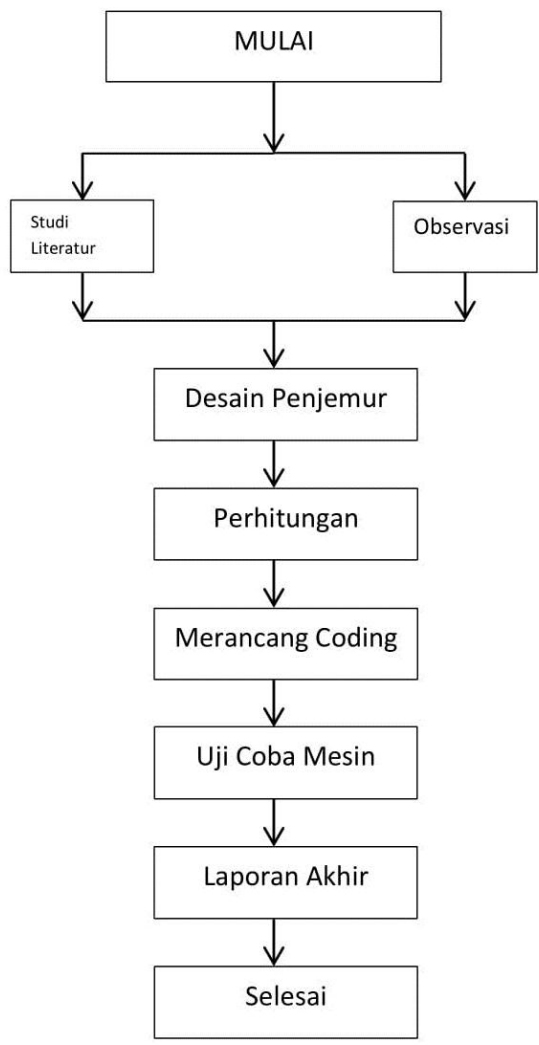

Gambar 1. Proses pembuatan alat pengering

Flowchart akan dimulai dengan melakukan studi literasi, mengumpulkan rumus yang dibutuhkan untuk realisasi dari alat penjemur. Membutuhkan rumus seberapa luas penampang dan daya tampung produk yang dapat dikeringkan di alat tersebut, dan dibutuhkan berapa lama untuk mengisi baterai dari panel surya sebagai sumber daya listrik. Selanjutnya dilakukan observasi terhadap masalah yang sering dialami produsen saat menjemur dari mendung, cuaca hujan, hingga gangguan hama menjadi masalah pokok pada produsen. Sehingga produsen membutuhkan waktu yang lebih lama dari biasanya, hal ini akan mengakibatkan naiknya harga produk. Desain alat penjemur ini dirancang menggunakan program Autocad Inventor. Alat penjemur ini memiliki keunggulan dimana alat penjemur ini bisa bebas dari hujan dan hama, dikarenakan terdapat tutup yang terbuat dari akrilik transparan untuk melindungi produk. Alat ini juga dirancang untuk dapat melakukan pengeringan di malam hari, dengan lampu pijar dan kipas angin komputer sebagai alat untuk mengatur suhu di dalam ruang alat. Arduino menjadi motherboard untuk memerintah pengatur suhu yang akan dikonfigurasikan ke lampu pijar dan $P C$ fan. Panel surya berperan sebagai sumber daya yang nantinya daya tersebut akan disimpan ke aki atau inverter, sehingga produsen bisa menghidupkan alat penjemur di malam hari. Sistem ini dapat meningkatkan produsen untuk menghasilkan lebih banyak produk karena produsen dapat menjamur di siang hari dan malam hari. 


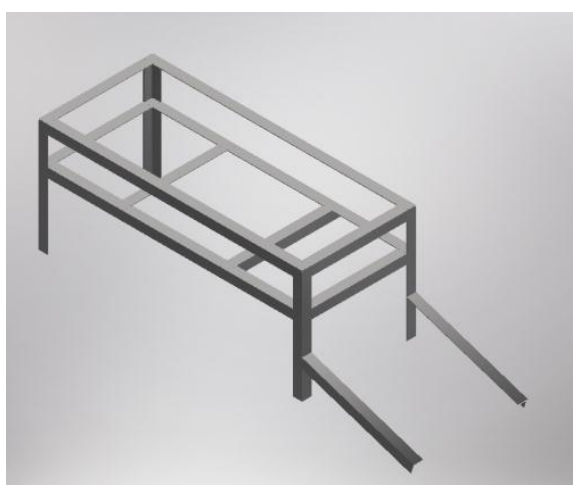

Gambar 2. Rancangan frame alat pengering

Frame alat pengering terbuat dari aluminium sehingga ringan dan mudah dipindahkan. Famer ini memiliki ukuran luas permukaan yang fleksibel tergantung kebutuhan produsen, namun pada desain ini menggunakan ukuran 300x700mm

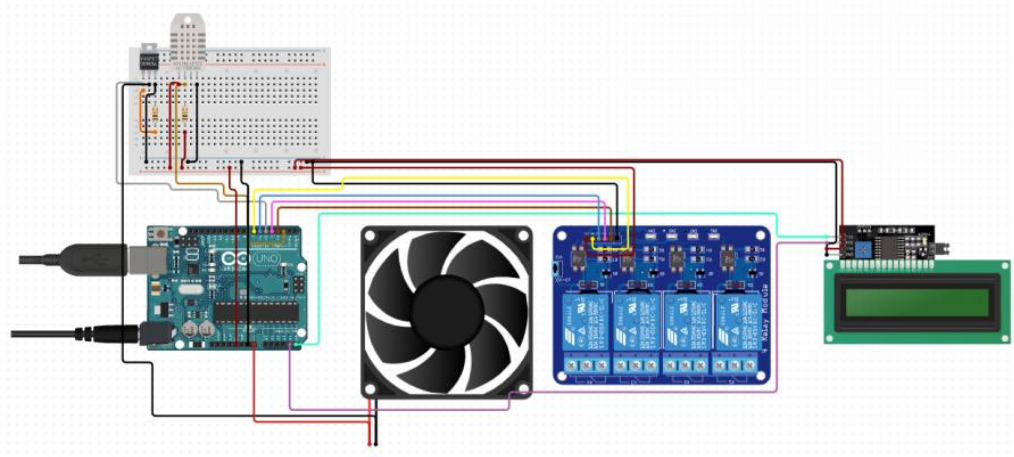

Gambar 3. Rangkaian arduino

Menggunakan arduino mega sebagai motherboard untuk mengontrol suhu dalam ruang alat. Menggunakan kipas kecil computer dan 4 buah lampu pijar, lampu pijar tersebut akan dipararelkan dengan 4 buah relay pada rangkaian arduino.

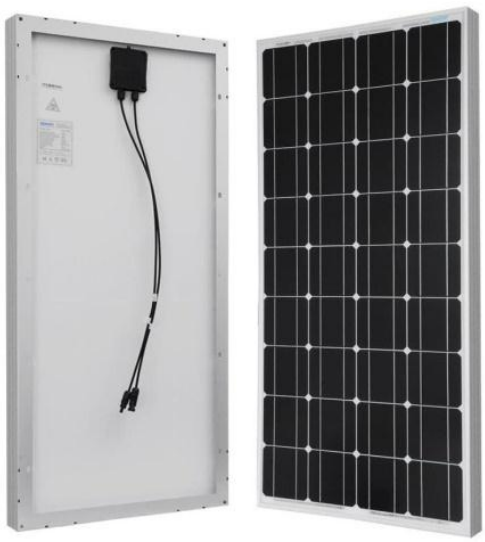

Gambar 4. Panel surya yang akan digunakan

Menggunakan panel surya dengan ukuran 1020x670x30mm dapat menghasilkan hingga 100W daya. Selanjutnya energi matahari tersebut akan di control oleh Solar charge controller yang selanjutnya akan disimpan di Aki.

Table 1. Komponen elektrik yang dibutuhkan [3]

\begin{tabular}{ccc}
\hline No & Komponen & Jumlah \\
\hline 1 & Panel Surya 20-100WP & 1 pcs \\
\hline
\end{tabular}


Procedia of Engineering and Life Science Vol.1 No. 1 March 2021

Seminar Nasional \& Call for Paper Fakultas Sains dan Teknologi (SENASAINS $1^{\text {st }}$ )

Universitas Muhammadiyah Sidoarjo

\begin{tabular}{ccc}
\hline 2 & Solar Charger Controller & $1 \mathrm{pcs}$ \\
\hline 3 & Aki 12V 7-33AH & $1 \mathrm{pcs}$ \\
\hline 4 & Arduino mega 2560 Rev3 & $1 \mathrm{pcs}$ \\
\hline 5 & Pc Fan 12V & $2 \mathrm{pcs}$ \\
\hline 6 & Lampu Pijar & $2-4 \mathrm{pcs}$ \\
\hline 7 & Relay Module 4-Ch & $1 \mathrm{pcs}$ \\
\hline 8 & LCD Display 16x2 & $1 \mathrm{pcs}$ \\
\hline 9 & Wall Adapter Power Supply & $1 \mathrm{pcs}$ \\
\hline 10 & DHT22/11 & $1 \mathrm{pcs}$ \\
\hline
\end{tabular}

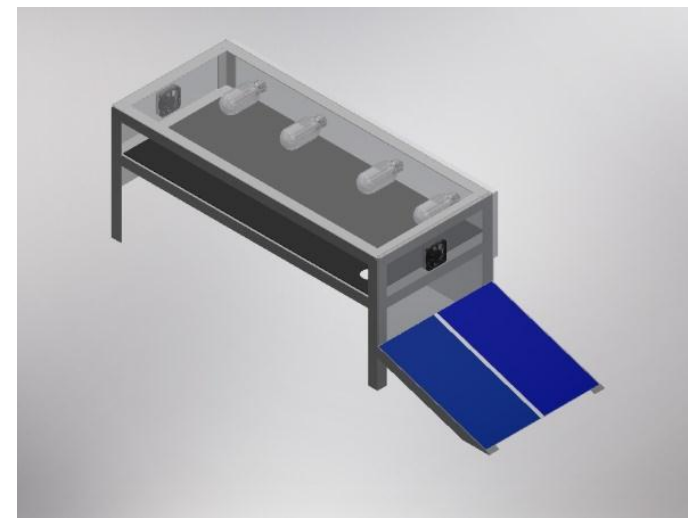

Gambar 5. Rancang bangun alat pengering mekanis keseluruhan

\section{Hasil dan Pembahasan}

Pada rancang bangun alat pengering mekanis ini di desain menggunakan software Autodeks Inventor. Pada hasil dan pembahasan akan dicari berapa kapasitas yang mampu di tampung oleh alat pengering, mencari laju pengeringan, energi surya yang dibutuhkan untuk pengeringan, serta mencari energi listrik yang dibutuhkan untuk menggerakkan lampu pijar dan $P C$ fan.

Pada rancang bangun alat pengering yang telah didesain menggunakan luas $300 \times 700 \mathrm{~mm}$ sehingga didapati kapasitas yang dapat ditampung sebagai berikut [4]:

$$
\begin{aligned}
& \text { luas }=p \cdot l \\
& \text { Dimana: } \\
& P=\text { Panjang alat pengering }(\mathrm{mm}) \\
& L=\text { luas alat pengering }(\mathrm{mm}) \\
& \text { Maka } \\
& \text { luas }=700 \times 300=210000 \mathrm{mn}^{2}
\end{aligned}
$$

Sehingga luas yang didapati dari rancang bangun adalah $210000 \mathrm{~mm}^{2}$, selanjutnya dicari kapasitas dengan membagi luas permukaan produk yang akan dikeringkan. Rengginang akan sebagai contoh produknya, diasumsikan diameter rengginag sebesar 70mm sehingga didapati hasil yaitu:

kapasitas $=\frac{\text { luas alat }}{\text { luas produk }}$

Dimana:

Luas alat $=210000 \mathrm{~mm}^{2}$

Luas Produk $=154 \mathrm{~mm}^{2}$

$$
\begin{aligned}
& \text { Maka } \\
& \text { kapasitas }=\frac{210000 \mathrm{~mm}^{2}}{15400 \mathrm{~mm}^{2}}=13.6
\end{aligned}
$$

Sehingga dapat diketahui bahwa dengan memiliki alat pengering sesuai rancang bangun diatas, kapasitas yang dapat ditampung oleh alat tersebut ialah 13 pcs rengginang dengan diameter $70 \mathrm{~mm}$. 
Selanjutnya akan mencari laju pengeringan yang dapat dilakukan oleh alat pengering mekanis, persamaan yang digunakan sebagai berikut [5]:

$$
\begin{aligned}
& L P=\frac{M_{w o}-M_{w i}}{\Delta t} \\
& \text { Dimana: } \\
& L P \quad=\text { laju pengeringan }(\% \mathrm{bk} / \mathrm{jam}) \\
& \mathrm{M}_{\mathrm{wo}}=\text { kadar air awal produk }(\% \mathrm{bk}) \\
& \mathrm{M}_{\mathrm{wi}}=\text { kadar air akhir produk }(\% \mathrm{bk}) \\
& \Delta \mathrm{t} \quad=\text { lama waktu pengeringan }(\mathrm{jam})
\end{aligned}
$$

Diasumsikan produk yang akan dikeringkan adalah ikan asin, karena ikan asin memiliki kadar air yang lebih banyak dari rengginang. Rata-rata kadar air pada ikan asin patin ialah 28.03\% sampai 35.59\% [6] dengan kadar garam mencapai 5\%. Diasumsikan kadar air pada awal pengeringan adalah 35\% dan kadar akhir setelah pengeringan ialah $29 \%$ dengan lama pengeringan dibawah matahari diasumsikan 10 jam. Sehingga didapati hasil kelajuannya sebagai berikut:

$$
L P=\frac{35 \%-29 \%}{10 j a m}=\frac{6 \%}{10 j a m}=0.6 \frac{\%}{\mathrm{jam}}
$$

Sehingga dapat diketahui bahwa kelajuan dalam pengeringan dengan matahari dapat menghilangkan $6 \%$ kadar air dalam 10 jam pengeringan dibawah matahari, $0.6 \%$ per jam adalah hasil yang masih tergolong kecil, sehingga produsen memerlukan minimal 2 hari untuk melakukan pengeringan pada ikan asin. Selanjutnya akan dicari energi surya atau matahari yang dibutuhkan untuk pengeringan sebagai berikut [7]:

$$
\begin{aligned}
& \text { qrs }=A \cdot I r \cdot t \\
& \text { Dimana: } \\
& \text { Qrs =energi surya yang dibutuhkan untuk pengeringan }(\mathrm{J}) \\
& \text { A =luas permukaan yang terkena radiasi }\left(\mathrm{m}^{2}\right) \\
& \text { Ir =intensitas radiasi marahati }\left(\mathrm{Watt} / \mathrm{m}^{2}\right) \\
& \mathrm{t} \quad=\text { waktu yang dibutuhkan untuk pengeringan (detik) }
\end{aligned}
$$

Diasumsikan luas permukaan yang terkena radiasi adalah $210000 \mathrm{~mm}^{2}$ atau $0.21 \mathrm{~m}^{2}$. Sedangkan untuk intensitas radiasi matahari diambil dari rata-rata intensitas di Indonesia yaitu $4.8 \mathrm{~kW} / \mathrm{m}^{2}$ [8] atau $4800 \mathrm{~W} / \mathrm{m}^{2}$ sedangkan untuk waktu pengeringan diasumsikan 10 jam atau 36000 detik. Sehingga energi yang dibutuhkan adalah sebagai berikut:

$$
q r s=0.21 \mathrm{~m}^{2} \cdot 4800 \frac{W}{\mathrm{~m}^{2}} \cdot 36000 \mathrm{sec}=36288000 \mathrm{~J} \text { atau } 36288 \mathrm{~kJ}
$$

Lalu dari energi surya yang didapati akan diolah oleh Solar charge controller yang berfungsi sebagai pengatur arus masuknya ke baterai atau aki agar tidak overcharging. Aki akan menyimpan daya dari Solar charge controller yang selanjutnya akan mengaliri listrik untuk lampu pijar dan $P C$ fan. Energy listrik yang dibutuhkan dapat dicari dengan persamaan sebagai berikut [9]:

$$
Q=3.6 \cdot p_{k} \cdot t
$$

\footnotetext{
Dimana:

Q =energi listrik untuk menggerakan controller $(\mathrm{J})$

$\mathrm{P}_{\mathrm{k}} \quad$ =daya listrik (Watt)

$\mathrm{t} \quad$ =waktu pengeringan (jam)
}

Diasumsikan daya listrik yang dihasilkan adalah 100 watt diambil dari spesifikasi panel surya yang digunakan, waktu pengering yang dibutuhkan adalah 10 jam. Sehingga energi listrik yang dibutuhkan adalah sebagai berikut:

$$
Q=3.6 \cdot 100 \mathrm{Watt} \cdot 10 \mathrm{jam}=3600 \mathrm{~J}
$$




\section{KESIMPULAN}

Luas permukaan alat pengering adalah $210000 \mathrm{~mm}^{2}$. Kapasitas produk yang dapat ditampung oleh alat pengering mekanis ialah 13 pcs rengginang dengan asumsi memiliki diameter $7 \mathrm{~cm}$. Laju pengeringan dengan matahari adalah $0.6 \%$ perjamnya. Energi surya atau matahari untuk pengeringan selama 10 jam yang dibutuhkan ialah $36288 \mathrm{~kJ}$. Energi listrik yang dibutuhkan untuk menggerakkan controller arduino dalam 10 jam adalah $3600 \mathrm{~J}$.

\section{UCAPAN TERIMA KASIH}

Kami ucapkan terimakasih pada dosen program studi S1 Teknik Mesin universitas Muhammadiyah Kalimantan Timur yang membantu memberi masukan agar tersusunnya paper ini dan terimaksih kepada Mahasiswa yang berperan dalam mendesain alat pengering mekanis ini dan kami ucapkan terimaksaih kepada semua pihak yang yang telah membantu tersusunya paper ini.

\section{REFERENSI}

[1] Mukkun, Y. (2016). PEMBUATAN ALAT PENGERING IKAN RAMAH LINGKUNGAN DENGAN MENGGUNAKAN PANEL SURYA. Jurnal Ilmiah FLASH Volume 2 Nomor 2 , 47.

[2] Sari Farah Dina, F. H. (2013). KAJIAN BERBAGAI METODE PENGERINGAN UNTUK PENINGKATAN MUTU BIJI KAKAO INDONESIA. Jurnal Riset Industri Vol. 7 No.1, 37.

[3] Shafiudin, S. (2016). PEMANTAUAN RUANG INKUBATOR PENETASAN TELUR AYAM DENGAN BERBASIS TELEMETRI MENGGUNAKANARDUINO UNO R3. Jurnal Nasional Teknik Elektro Vol: 5, No. 1, 28-29.

[4] Wening, T. (2020, Agustus 13). Rangkuman dan Soal Keliling Bangun Datar: Persegi, Persegi Panjang, Segitiga. Dipetik Maret 6, 2021, dari Bobo.id: https://bobo.grid.id/read/082287911/rangkuman-dan-soalkeliling-bangun-datar-persegi-persegi-panjang-segitiga-materi-belajar-dari-rumah-tvri-kelas-4-6?page=all

[5] Wilhelm, L. R. (2005). Food \& process engineering technology. Milwaukee: St. Joseph, MI : American Society of Agricultural Engineers

[6] Hardoko. (2018). KONVERSI IKAN ASIN MENJADI NUGGET BERSERAT PANGAN DENGAN TAMBAHAN AMPAS TAHU DAN BEBERAPA JENIS BINDER. JPHPI 2018, Volume 21 Nomor 1, 55.

[7] Firmansyah Burlian, A. F. (2011). KAJI EKSPERIMENTAL ALAT PENGERING KERUPUK TENAGA SURYA TIPE BOX MENGGUNAKAN KOSENTRATOR CERMIN DATAR. Prosiding Seminar Nasional AVoER ke-3, 99.

[8] Rahardjo, I. (2010). ANALISIS POTENSI PEMBANGKIT LISTRIK TENAGA SURYA DI INDONESIA . Strategi Penyediaan Listrik Nasional Dalam Rangka Mengantisipasi Pemanfaatan, 43

[9] Panggabean, T. (2017). Kinerja Pengeringan Gabah Menggunakan Alat Pengering Tipe Rak dengan Energi Surya, Biomassa, dan Kombinasi . AGRITECH, Vol. 37, No. 2, 231. 